\title{
The Psychometric Properties of a Jordanian Version of Overexcitability Questionnaire-Two, OEQII
}

\author{
Sabah Hasan Al-Onizat \\ Faculty of Education, The World Islamic Sciences \& Education University (WISE), Amman, Jordan \\ Email:dr_sabah@hotmail.com
}

Received September 29 ${ }^{\text {th }}, 2012$; revised October $30^{\text {th }}, 2012$; accepted November $16^{\text {th }}, 2012$

\begin{abstract}
This study deals with the psychometric properties and derivation of norms for an Arabic version of the Overexcitability Questionnaire-Two, OEQII. The standardization sample consisted of 289 students (159 males, 130 females) ranging from 15 - 17 years in age. Factor analysis and one-way ANOVA reveals a good construct, factorial, and discriminatory validity. The Cronbach-a formula was used to estimate internal consistency coefficients. All the results indicate acceptable reliability for the OEQII. The Overexcitabilities scores were distributed normally in terms of the age range. And the Deviation for the Overexcitabilities degrees and percentiles were calculated for each group of the sample. Finally, results indicated no statistical difference at $(\alpha=0.05)$ among males and females students in the total scale, the female tended to do better in the overall average of the OEQII and in Sensual and in Emotional Overexcitability: Overall, the OEQII appears to have acceptable psychometric characteristics allowing for use instrument to promote the use of strength-based learning activities to enhance instructional practice and personal improvement.
\end{abstract}

Keywords: Psychometric Properties; Overexcitability; Overexcitability Questionnaire-Two (OEQII)

\section{Background}

The process of identification and classification of individuals as gifted or talented is the main step of any project aimed this group in the education system and to determine whether these students receive the appropriate services needed to foster there development, especially when we know that about $70 \%$ of gifted student are not receiving the appropriate services because there was a dearth of research and data collection establishing indices for creative population that would make such identification possible (Renzulli, 1978; Tannenbaum, 1983).

In a review of educational literature of the methods and tools for detection gifted, we find that most of these tools focus on the mental/cognitive aspect, as reflected in tests of intelligence, academic achievement or tests of school readiness, and in some cases using rating lists of the behavioral and emotional aspects that estimated by teachers, parents or peers, which may does not have the significance of reliability and validity.

And due to the a shortness and limitations in the tools and criteria of detection gifted, researchers and educator turned their attention to other ways may be more feasible; through the personality characteristics based on Dabrawski's Theory of Positive Disintegration (TPD) (1964) which stated that people born with a higher level of "development potential" than others.

Many definitive research and the naturalistic observation have led to the belief that intensity, sensitivity and Overexcitability are primary characteristics of the highly gifted. These observations are supported by parents and teachers who notice distinct behavioral and constitutional differences between highly gifted children and their peers. The work of Kazimierz Dabrowski provides an excellent framework with which to understand these characteristics. Dabrowski, a psychiatrist and psychologist, developed the Theory of Positive Disintegration as a response to the prevalent psychological theories of his time.
He believed that conflict and inner suffering were necessary for advanced development - for movement towards a hierarchy of values based on altruism - for movement from "what is" to "what ought to be". Dabrowski also observed that not all people move towards an advanced level of development but that innate ability/intelligence combined with overexcitability (OE) were predictive of potential for higher-level development

In the theory, three factors play a role in higher-level psychological functioning - developmental potential: 1) Constitution or heredity; 2) Environmental or society; 3) Autonomous or self determined. And these characteristics are termed "Over-excitability" (OE's) or "super-sensitivities": "responses to a variety of stimuli may markedly exceed the value of an average response, they may last significantly longer (although this is not a necessary attribute of over-excitability), and they may occur with greater frequency" (Dabrowski, 1996: p. 71). Overexcitability indicates increased frequency, intensity, and duration of response in one or more of the following areas: emotional, intellectual, imaginational, sensual, and psychomotor (Dabrowski \& Piechowski, 1977; Piechowski, 2006):

- Psychomotor Overexcitability: is a manifestation of a heightened energy level, appears as restlessness, rapid and pressured speech, predilection for violent games and sports, pressure for action.

- Sensual Overexcitability: is a manifestation of a heightened sensitivity to sensory stimuli, particularly to sensory pleasure, the unusual intensity of reactions to one sensual sphere (visual, auditory, tactile, or olfactory), encompasses the whole character structure and all senses equally.

- Imaginational Overexcitability: is an imbalance in information processing that is skewed toward internal, image-based mode, with a relative exclusion of sensual, affective and psychomotor spheres. For individuals with a dominant im- 
aginational OE, external stimuli matter usually as fodder for their imagination, rather than on their own merit.

- Intellectual Overexcitability: is the rarest type of OE and one with the least clinical implications. In this type of OE, a person's receiving and processing information as well as decision-making are localized in the cognitive sphere.

- Emotional Overexcitability: is a function of experiencing emotional relationships. The relationships can manifest themselves as strong attachment to persons, living things, or places.

A person may possess none, one, or many of these overexcitabilities.

Dabrowski hypothesized that these characteristics of Overexcitability were more prevalent in gifted individuals than in the general population, Silverman (1993) also suggested that these intensities, often manifested by gifted and talented students, may be expressed in displays of intense energy, enthusiasm, absorption in their chosen pursuits, vivid imagination, and strong sensual reactions to stimuli; although the gifted are also known to be emotionally vulnerable (Hollingworth, 1942; Silverman, 1994).

\section{Statement of the Problem}

A valid and reliable tool such as Overexcitability scale would provide Jordanian decision makers, teachers and parents a clearer, more comprehensive, insight into Jordanian student. There is a need however, to derive the norms for a Jordanian version of Overexcitability scale, while investigating the validity and reliability of such an instrument.

And we will answer the following questions:

1) Are there significant differences at the level of statistical significance $(\alpha \leq 0.05)$ in the performance of students on the scale of Overexcitability, and its five dimensions, according to the variable of the student group (gifted, non-gifted)?

2) Are there significant differences at the level of statistical significance $(\alpha \leq 0.05)$ in the performance of students on the scale of Overexcitability, and its five dimensions, according to the variable of the student sex (male, female)?

3) Are there significant differences at the level of statistical significance $(\alpha \leq 0.05)$ in the performance of students on the scale of Overexcitability, and its five dimensions, according to the variable of the student age (seventh, eleventh)?

\section{The Importance of the Study}

1) Trying to get to know and reveal the psychological and behavioral characteristics of gifted students compared with the non-gifted students by using Overexcitability scale, and according the variable of the sex and age.

2) Emphasis on the importance of focusing on the psychological and behavioral characteristics as a criterion in disclosure of gifted students.

3) Emphasis on the strong relationship between psychological and behavioral characteristics and the appropriate type of educational and counseling programs.

4) Scarcity of Arab studies that dealt with the Overexcitability as a tool for discover the gifted student and compare them with non-gifted student.

\section{The Limitation of the Study}

The possibility of generalize the results of the current study, limited by the following elements:

1) Limited study on a sample of gifted students in Jubilee School and a similar sample of its non-gifted students in general schools in Amman (one male and one female) of ninth and eleventh grade and aged (15 - 17 years), and the possibility of generalize the results by the characteristics of the study sample, and how much it represent the study population.

2) The nature of student Understanding of the items of Overexcitability scale.

3) The objectivity of the study participants in their estimates and their responses on Overexcitability scale.

\section{General Description of the Overexcitability Questionnaire-Two, OEQII}

The OEQ-II is a 50 -item, self-rating questionnaire to measure OE (Bouchet \& Falk, 2001; Falk, Lind, Miller, Piechowski, \& Silverman, 1999). Ten items that assess each of the five OEs (emotional, intellectual, imaginational, sensual, and psychomotor) are randomly distributed throughout the instrument. Respondents are asked to rate items on a scale of 1 (Not at all like me) to 5 (Very much like me).

Examples of items include "I worry a lot", "Theories get my mind going", and "I'm a competitive person". Scores are summed and averaged for each OE. Internal reliability for OEs range from Cronbach's alpha $=0.85$ for imaginational $\mathrm{OE}$ to 0.98 for sensual and intellectual OE. Content validity was established by principal components factor analysis with varimax rotation showing simple structure and item loadings all above 0.50 (Falk et al., 1999).

\section{Statement of the Problem}

The purpose of the this study is to develop a statistically reliable and valid instrument that will measure the Overexcitabilities in elementary school aged children, with predictive validity for identifying gifted student, to provide teachers and parents a clearer and insight into Jordanian student personality differences. There is a need however, to derive the norms for a Jordanian version of Overexcitability Questionnaire-Two, OEQII, while investigating the validity and reliability of such an instrument.

\section{Methods}

This study adapts and validates a Jordanian version of OEQII. This part of study discusses the research methodology and techniques used, the rational for the methodology used and describes the considerations influencing the development of research techniques and procedures.

\section{Subjects}

A sample of secondary-aged students $(\mathrm{N}=289)$, was randomly selected from nights and eleventh grades in Amman (115 gifted students from jubilee School for gifted students, 174 non-gifted students from public schools) and the range of their ages between 15 - 17 years, The study employed random stratified sample technique in order to represent the characteristic of the whole population. And the Table 1 shows the total number of secondary student according to their regions in Jordan. 


\section{Procedures}

The Overexcitability Questionnaire-Two, OEQII was administered to participants in their classroom environments. The researcher explained the purpose and importance of their participation in this study. In addition, the participants were assured of the confidentiality of their responses which would only be used for research purposes. Question booklets were distributed and participants were asked to fill in the information needed and then participants were instructed how to answer them. Approximately 30 minutes were taken to complete the test. Responses were entered into the computer for statistical analysis using SPSS (Version 19 package). After data analysis results were discussed. Based on findings, suggestions were made for further research and for instructional processes.

\section{Results}

\section{Validity Content Validity}

The first step taken to establish the validity of Jordanian version of OEQII was a translation and back-translation of the English language version into Arabic. This was followed by content validity using expert judgment and a pilot study using items into Arabic. Stringent instrument development was involved in item construction, scale composition, sub-scales creation and expert judgment to improve content validity. The

Table 1.

Total number of secondary student according to their regions in Jordan.

\begin{tabular}{cccccccc}
\hline \multirow{2}{*}{ Grade } & \multicolumn{3}{c}{ Gifted students } & \multicolumn{3}{c}{ Non-gifted students } & \multirow{2}{*}{ Total } \\
\cline { 2 - 6 } & Male & Female & Total & Male & Female & Total & \\
\hline 9th grad & $\mathbf{3 2}$ & $\mathbf{1 8}$ & $\mathbf{5 0}$ & 46 & 29 & 75 & 125 \\
11th grad & 32 & 33 & 65 & 49 & 50 & 99 & 164 \\
Total & 64 & 51 & 115 & 95 & 79 & 174 & 289 \\
\hline
\end{tabular}

translated Jordanian version of OEQII was reviewed by ten experts at Jordan University and Arabian Amman University. Their comments and suggestions were used to modify and refine the items in the Jordanian version; the purpose of study was to determine the overall reliability for the Arabic version of MIDAS and the reliabilities of its subscales. The reliability coefficient computed as obtained using test-retest method.

\section{Factorial Validity}

Correlation coefficients were determined for each item with the total degree of each intelligence. Table 2 shows results greater than 0.39 . The results appear supportive of the scale construction, where the Correlation coefficients ranged between (0.30 - 0.69) for the Imagination Overexcitability, and between $(0.48-0.69)$ for the Intellectual Overexcitability, and between $(0.34-0.67)$ for the Sensual Overexcitability, and between (0.46 - 0.78) for the Psychomotor Overexcitability, and between $(0.37-0.60)$ for the Emotional Overexcitability.

\section{Discrimination Validity}

First: Discrimination according to the type of students (gifted and non-gifted students):

To examine differences in the degree of Overexcitabilities among gifted students and non- gifted students the t-test was applied to examine the capacity of the scale to distinguish between these two categories, and the results are shown in the Table 3.

And the results show the following:

- There is a statistically significant difference at the 0.05 level, at the overall average of the Overexcitability, The value of $\mathrm{T}$ is (-4.55), and the arithmetic averages of this difference was in favor of gifted students with average is (179.30) while the averages of the non- gifted students is (167.43).

- There is a statistically significant difference at the 0.05 level at the averages of Psychomotor Overexcitability the

Table 2.

Correlation coefficients of OEQII items with the total degree of the overall Overexcitabilities.

\begin{tabular}{|c|c|c|c|c|c|c|c|c|c|}
\hline \multicolumn{2}{|c|}{ Imagination over } & \multicolumn{2}{|c|}{ Intellectual over } & \multicolumn{2}{|c|}{ Sensual over } & \multicolumn{2}{|c|}{ Psychomotor over } & \multicolumn{2}{|c|}{ Emotional over } \\
\hline Item num & Corr coeff & Item num & Corr coeff & Item num & Corr coeff & Item num & Corr coef & Item num & Corr coef \\
\hline 1 & 0.57 & 2 & 0.56 & 3 & 0.34 & 7 & 0.63 & 6 & 0.58 \\
\hline 4 & 0.56 & 5 & 0.50 & 8 & 0.57 & 10 & 0.49 & 11 & 0.53 \\
\hline 9 & 0.57 & 12 & 0.66 & 13 & 0.55 & 15 & 0.67 & 17 & 0.37 \\
\hline 14 & 0.62 & 16 & 0.48 & 32 & 0.67 & 18 & 0.53 & 26 & 0.52 \\
\hline 20 & 0.48 & 19 & 0.67 & 37 & 0.49 & 29 & 0.53 & 31 & 0.49 \\
\hline 21 & 0.30 & 23 & 0.69 & 38 & 0.36 & 39 & 0.46 & 35 & 0.57 \\
\hline 22 & 0.45 & 25 & 0.51 & 45 & 0.67 & 42 & 0.36 & 44 & 0.60 \\
\hline 24 & 0.69 & 27 & 0.48 & 46 & 0.50 & 50 & 0.78 & 49 & 0.43 \\
\hline 28 & 0.44 & 30 & 0.52 & & & & & & \\
\hline 33 & 0.34 & 36 & 0.49 & & & & & & \\
\hline 34 & 0.53 & 40 & 0.52 & & & & & & \\
\hline 41 & 0.40 & 43 & 0.53 & & & & & & \\
\hline 47 & 0.48 & & & & & & & & \\
\hline
\end{tabular}

Note: Correlation coefficient: corr coeff. Over: Overexcitability. 
value of $(\mathrm{T})$ was $(-2.11)$, and the arithmetic averages of this difference was in favor of gifted students with average (35.89) while the average of non- gifted students is (34.27).

- There is a statistically significant difference at the 0.05 level at the averages of Sensual Overexcitability the value of $(\mathrm{T})$ was $(-3.81)$, and the arithmetic averages of this difference was in favor of gifted students with average (37.35) while the average of non-gifted students is (34.56).

- There is a statistically significant difference at the 0.05 level at the averages of Intellectual Overexcitability the value of $(\mathrm{T})$ was $(-6.04)$, and the arithmetic averages of this difference was in favor of gifted students with average (38.47) while the average of non-gifted students is (33.68).

Second: Discrimination according to the gender (male and female students):

The arithmetic mean and standard deviations for scores of individuals on multiple Intelligences according to the Gender,
Table 4 shows the results.

The result of analysis shows the follows:

- There is a statistically significant difference at the 0.05 level in the overall average of the Overexcitabilities between male and female the value of $(\mathrm{T})$ was $(-2.35)$, in favor of female with arithmetic average (176.88) while the average for males (169.99).

And there are differing in degrees of some Overexcitabilities, the female have a higher performance in Sensual Overexcitability with averages (37.08), while the males averages (35.06), and in Emotional Overexcitability with averages (38.08), while the males averages (34.87).

Third: Discrimination according to the age (male and female students):

The arithmetic mean and standard deviations for scores of individuals on Overexcitabilities according to the Gender, Table 5 shows the results.

Table 3.

The results of t-test to examine differences in the degree of Overexcitabilities among gifted and non- gifted students.

\begin{tabular}{|c|c|c|c|c|c|c|}
\hline \multirow{2}{*}{ Type of Overexcitability } & \multicolumn{2}{|c|}{ Gifted } & \multicolumn{2}{|c|}{ Non-gifted } & \multirow{2}{*}{ T value } & \multirow{2}{*}{ Sig level } \\
\hline & Arith mean & Stand dev & Arith mean & Stand dev & & \\
\hline Psychomotor & 35.89 & 5.78 & 34.27 & 5.78 & -2.11 & 0.036 \\
\hline Sensual & 37.35 & 5.68 & 34.56 & 5.44 & -3.81 & 0.000 \\
\hline Imagination & 30.97 & 6.62 & 29.71 & 6.51 & -1.45 & 0.147 \\
\hline Intellectual & 38.47 & 5.30 & 33.68 & 6.38 & -6.04 & 0.000 \\
\hline Emotional & 36.62 & 5.82 & 35.21 & 5.80 & -1.83 & 0.068 \\
\hline Total & 179.30 & 17.54 & 167.43 & 20.86 & -4.55 & 0.000 \\
\hline
\end{tabular}

Note: Arith mean: arithmetic mean, stand dev: standard deviation.

Table 4.

The mean and standard deviations of the Overexcitabilities items according to the gender.

\begin{tabular}{|c|c|c|c|c|c|c|}
\hline \multirow{2}{*}{ Type of Overexcitability } & \multicolumn{2}{|c|}{ Male } & \multicolumn{2}{|c|}{ Female } & \multirow{2}{*}{$\mathrm{T}$ value } & \multirow{2}{*}{ Sig level } \\
\hline & Stand dev & Arith mean & Stand dev & Arith mean & & \\
\hline Psychomotor & 35.18 & 6.01 & 34.06 & 5.22 & 1.34 & 0.183 \\
\hline Sensual & 35.06 & 5.51 & 37.08 & 5.93 & -2.49 & 0.013 \\
\hline Imagination & 29.70 & 6.67 & 31.47 & 6.13 & -1.88 & 0.061 \\
\hline Intellectual & 35.20 & 6.49 & 36.20 & 6.22 & -1.08 & 0.281 \\
\hline Emotional & 34.87 & 5.67 & 38.08 & 5.65 & -3.93 & 0.000 \\
\hline Total & 169.99 & 21.06 & 176.88 & 18.01 & -2.35 & 0.019 \\
\hline
\end{tabular}

Table 5.

The mean and standard deviations of the Overexcitability items according to the age.

\begin{tabular}{|c|c|c|c|c|c|c|}
\hline \multirow{2}{*}{ Type of Overexcitability } & \multicolumn{2}{|c|}{$15-16$} & \multicolumn{2}{|c|}{$17-18$} & \multirow{2}{*}{$\mathrm{T}$ value } & \multirow{2}{*}{ Sig level } \\
\hline & Arith mean & Stand dev & Arith mean & Stand dev & & \\
\hline Psychomotor & 35.11 & 5.82 & 34.69 & 5.83 & 0.56 & 0.577 \\
\hline Sensual & 35.19 & 5.53 & 35.93 & 5.80 & -1.00 & 0.319 \\
\hline Imagination & 30.44 & 6.33 & 29.97 & 6.76 & 0.55 & 0.584 \\
\hline Intellectual & 35.19 & 6.39 & 35.69 & 6.46 & -0.61 & 0.542 \\
\hline Emotional & 34.92 & 5.57 & 36.38 & 5.97 & -1.96 & 0.051 \\
\hline Total & 170.84 & 20.66 & 172.66 & 20.36 & -0.69 & 0.492 \\
\hline
\end{tabular}


The result of analysis shows the follows:

- There is no statistically significant difference at the 0.05 level in the overall average of the Overexcitabilities and each of Overexcitabilities according to the both age categories $(15-16)$ and $(17-18)$.

\section{Reliability}

The reliability of the OEQII has been examined in terms of internal consistency (Cronbach-a), and test-retest reliability. The results are shown below (Table 5).

Test-retest reliability coefficients ranged from 0.73 for Psychomotor Overexcitability to 0.85 for Imagination Overexcitability. The whole scale was 0.85 . The Internal consistency coefficients ranged from 0.74 for Psychomotor Overexcitability to 0.84 for Intellectual Overexcitability. The scale as a whole was 0.91. All results suggest that levels of variance are acceptable. As shown in the Table 6.

The effectiveness of the items of Jordanian adaptive version of Overexcitabilities scale:

The arithmetic mean, standard deviations, the mean percentage (difficulty coefficient) and the correlation coefficient of each item with their subscale degree (discrimination coefficient), the results show in the Tables 7-11.

The previous results show that all of the Overexcitability scale items have acceptable difficulty coefficient and discrimination coefficient degrees.

Is there a statistically significant correlation between the performance on each item of sub-scale and the total score of the Jordanian adaptive version of Overexcitabilities scale?

Table 12 show the results of the correlation coefficient of each item with the total score.

The difficulty coefficient for each item with the total score of the Overexcitabilities scale ranged between 0.27 and 0.60 , and all of them have a statistically significant at the 0.05 level.

What are the derived statistical criteria for the Jordanian adaptive version of Overexcitabilities scale?

To examine the normal distribution for the subscale of the Overexcitabilities scale, the KS test was used. The Table 13 shows the results.

The results of the KS test show that all of the degrees of the Overexcitabilities subscales distributed normally, and all the values of the significance level higher than 0.05 which it did not deviate in terms of statistics at the level of 0.05 for the normal distribution, it is shown also in the following Figure 1.

\section{Raw Grades of Overexcitabilities and Percentiles}

The following Tables $\mathbf{1 4}$ and $\mathbf{1 5}$ show the expected Overexcitabilities raw grades, the total of degrees and the correspond-

Table 6.

The reliability by internal consistency (Cronbach-a) and test-retest reliability.

\begin{tabular}{ccc}
\hline Type of Overexcitability & Internal consistency & Test-retest reliability \\
\hline Psychomotor Overexcitability & 0.74 & 0.73 \\
Sensual Overexcitability & 0.78 & 0.80 \\
Imagination Overexcitability & 0.80 & 0.85 \\
Intellectual Overexcitability & 0.84 & 0.77 \\
Emotional Overexcitability & 0.75 & 0.78 \\
Total Overexcitabilities & 0.91 & 0.85 \\
\hline
\end{tabular}

Table 7.

The mean and standard deviations for the Psychomotor Overexcitability items and their correlation coefficient.

\begin{tabular}{ccccc}
\hline & Arithmetic mean & Standard deviations & The percentage & Discrimination coefficient \\
\hline Psychomotor & 34.80 & 6.47 & 0.70 & 0.35 \\
2 & 3.59 & 1.11 & 0.72 & 0.60 \\
7 & 3.38 & 1.16 & 0.68 & 0.61 \\
10 & 3.65 & 1.15 & 0.73 & 0.68 \\
15 & 3.70 & 1.14 & 0.74 & 0.63 \\
18 & 3.22 & 1.15 & 0.64 & 0.43 \\
21 & 3.51 & 1.32 & 0.70 & 0.62 \\
29 & 3.21 & 1.16 & 0.64 & 0.45 \\
42 & 2.80 & 1.32 & 0.56 & 0.85 \\
50 & 4.24 & 0.95 & 0.70 & 0.50 \\
\hline
\end{tabular}

Note: The table shows that the difficulty coefficient for the Psychomotor Overexcitability items ranged between 0.56 and 0.85 , and the discrimination coefficient ranged between 0.35 and 0.68 . 


\section{S. H. AL-ONIZAT}

Table 8.

The mean and standard deviations for the Sensual Overexcitability items and their correlation coefficient.

\begin{tabular}{ccccc}
\hline & Arithmetic mean & Standard deviations & The percentage & Discrimination coefficient \\
\hline Sensual & 35.52 & 7.28 & 0.71 & 0.41 \\
3 & 3.80 & 1.08 & 0.76 & 0.60 \\
8 & 3.28 & 1.23 & 0.66 & 0.59 \\
13 & 3.47 & 1.12 & 0.69 & 0.48 \\
27 & 3.66 & 1.03 & 0.73 & 0.60 \\
32 & 3.18 & 1.24 & 0.64 & 0.57 \\
37 & 4.02 & 1.08 & 0.80 & 0.21 \\
38 & 3.63 & 1.12 & 0.73 & 0.68 \\
45 & 3.22 & 1.17 & 0.64 & 0.56 \\
46 & 3.30 & 1.13 & 0.66 & 0.59 \\
48 & 3.80 & 1.24 & 0.76 & \\
\hline
\end{tabular}

Note: The table shows that the difficulty coefficient for the Sensual Overexcitability items ranged between 0.64 and 0.80 , and the discrimination coefficient ranged between 0.21 and 0.68

Table 9.

The mean and standard deviations for the Imagination Overexcitability items and their correlation coefficient.

\begin{tabular}{ccccc}
\hline & Arithmetic mean & Standard deviations & The percentage & Discrimination coefficient \\
\hline Imagination & 30.66 & 8.23 & 0.61 & 0.69 \\
1 & 3.01 & 1.17 & 0.61 & 0.59 \\
4 & 2.69 & 1.23 & 0.54 & 0.63 \\
14 & 3.37 & 1.38 & 0.67 & 0.39 \\
20 & 2.39 & 1.32 & 0.48 & 0.50 \\
22 & 3.61 & 1.08 & 0.72 & 0.59 \\
24 & 2.89 & 1.27 & 0.58 & 0.51 \\
28 & 3.02 & 1.26 & 0.60 & 0.47 \\
33 & 2.54 & 1.38 & 0.51 & 0.52 \\
47 & 3.09 & 1.22 & 0.77 & 0.59 \\
\hline
\end{tabular}

Note: The table shows that the difficulty coefficient for the Imagination Overexcitability items ranged between 0.48 and 0.77 , and the discrimination coefficient ranged between 0.39 and 0.63 .

Table 10.

The mean and standard deviations for the Intellectual Overexcitability items and their correlation coefficient.

\begin{tabular}{ccccc}
\hline & Arithmetic mean & Standard deviations & The percentage & Discrimination coefficient \\
\hline Intellectual & 35.61 & 6.93 & 0.71 & 0.73 \\
5 & 3.67 & 1.15 & 0.73 & 0.63 \\
12 & 3.63 & 1.02 & 0.75 & 0.64 \\
16 & 3.76 & 1.19 & 0.67 & 0.64 \\
19 & 3.35 & 1.04 & 0.70 & 0.72 \\
23 & 3.52 & 1.11 & 0.67 & 0.65 \\
25 & 3.33 & 1.12 & 0.72 & 0.65 \\
30 & 3.62 & 1.11 & 0.73 & 0.63 \\
46 & 3.63 & 1.05 & 0.71 & 0.66 \\
43 & 3.57 & 1.08 & 0.71 & 0.65 \\
\hline
\end{tabular}

Note: The table shows that the difficulty coefficient for the Intellectual Overexcitability items ranged between 0.67 and 0.75 , and the discrimination coefficient ranged between 0.49 and 0.72 


\section{S. H. AL-ONIZAT}

Table 11.

The mean and standard deviations for the Emotional Overexcitability items and their correlation coefficient.

\begin{tabular}{ccccc}
\hline & Arithmetic mean & Standard deviations & The percentage & Discrimination coefficient \\
\hline Emotional & 35.61 & 6.66 & 0.71 & 0.52 \\
6 & 4.10 & 1.01 & 0.82 & 0.43 \\
9 & 3.19 & 1.19 & 0.64 & 0.59 \\
11 & 3.73 & 1.13 & 0.75 & 0.58 \\
17 & 3.44 & 1.36 & 0.69 & 0.63 \\
26 & 3.80 & 1.15 & 0.76 & 0.48 \\
31 & 3.51 & 1.12 & 0.70 & 0.72 \\
45 & 3.20 & 1.41 & 0.64 & 0.57 \\
44 & 3.45 & 1.17 & 0.69 & 0.41 \\
49 & 4.01 & 1.20 & 0.80 & 0.61 \\
\hline
\end{tabular}

Note: The table shows that the difficulty coefficient for the Emotional Overexcitability items ranged between 0.63 and 0.82 , and the discrimination coefficient ranged between 0.41 and 0.72 .

Table 12.

The correlation coefficient for each item of sub-scale with the total score of the Overexcitabilities scale.

\begin{tabular}{|c|c|c|c|c|c|c|c|c|c|}
\hline $\begin{array}{l}\text { Psychomotor } \\
\text { Overexcitability } \\
\text { items }\end{array}$ & $\begin{array}{c}\text { The } \\
\text { correlation } \\
\text { coefficient }\end{array}$ & $\begin{array}{c}\text { Sensual } \\
\text { Overexcitability }\end{array}$ & $\begin{array}{c}\text { The } \\
\text { correlation } \\
\text { coefficient }\end{array}$ & $\begin{array}{l}\text { Imagination } \\
\text { Overexcitability } \\
\text { items }\end{array}$ & $\begin{array}{c}\text { The correlation } \\
\text { coefficient }\end{array}$ & $\begin{array}{c}\text { Intellectual } \\
\text { Overexcitability }\end{array}$ & $\begin{array}{l}\text { The correlation } \\
\text { coefficient }\end{array}$ & $\begin{array}{c}\text { Emotional } \\
\text { Overexcitability } \\
\text { items }\end{array}$ & $\begin{array}{c}\text { The correlation } \\
\text { coefficient }\end{array}$ \\
\hline 2 & 0.29 & 3 & 0.37 & 1 & 0.41 & 5 & 0.35 & 6 & 0.42 \\
\hline 7 & 0.36 & 8 & 0.55 & 4 & 0.43 & 12 & 0.46 & 9 & 0.36 \\
\hline 10 & 0.46 & 13 & 0.49 & 14 & 0.49 & 16 & 0.52 & 11 & 0.47 \\
\hline 15 & 0.49 & 27 & 0.50 & 20 & 0.24 & 19 & 0.45 & 17 & 0.41 \\
\hline 18 & 0.43 & 32 & 0.52 & 22 & 0.50 & 23 & 0.53 & 26 & 0.51 \\
\hline 21 & 0.35 & 37 & 0.49 & 24 & 0.47 & 25 & 0.55 & 31 & 0.34 \\
\hline 29 & 0.48 & 38 & 0.35 & 28 & 0.43 & 30 & 0.51 & 35 & 0.51 \\
\hline 39 & 0.28 & 45 & 0.60 & 33 & 0.44 & 36 & 0.55 & 41 & 0.49 \\
\hline 42 & 0.46 & 46 & 0.44 & 34 & 0.55 & 40 & 0.54 & 44 & 0.27 \\
\hline 50 & 0.31 & 48 & 0.50 & 47 & 0.57 & 43 & 0.58 & 49 & 0.37 \\
\hline
\end{tabular}

Table 13.

The results of the KS test for the normal distribution.

\begin{tabular}{ccc}
\hline Subscales & KS value & Sig level \\
\hline Psychomotor & 0.94 & 0.34 \\
Sensual & 0.85 & 0.46 \\
Imagination & 1.13 & 0.16 \\
Intellectual & 1.17 & 0.13 \\
Emotional & 1.08 & 0.20 \\
Total Overexcitabilities & 0.64 & 0.81 \\
\hline
\end{tabular}

ing percentiles.

\section{Discussion}

The purpose of this study was to develop a statistically reliable and valid instrument to measure Overexcitabilities in elementary school aged children in Jordan, with predictive validity to identifying gifted children. Moreover, the validation of the original English version of Overexcitability Questionnaire-Two, OEQII has been examined via a series of investigations, which evaluate its construct, concurrent, and predictive validity. Whereas there is a subset of OEQII instrument that inquire the active participation and expressed enthusiasm for many of the Overexcitability activities. 
S. H. AL-ONIZAT
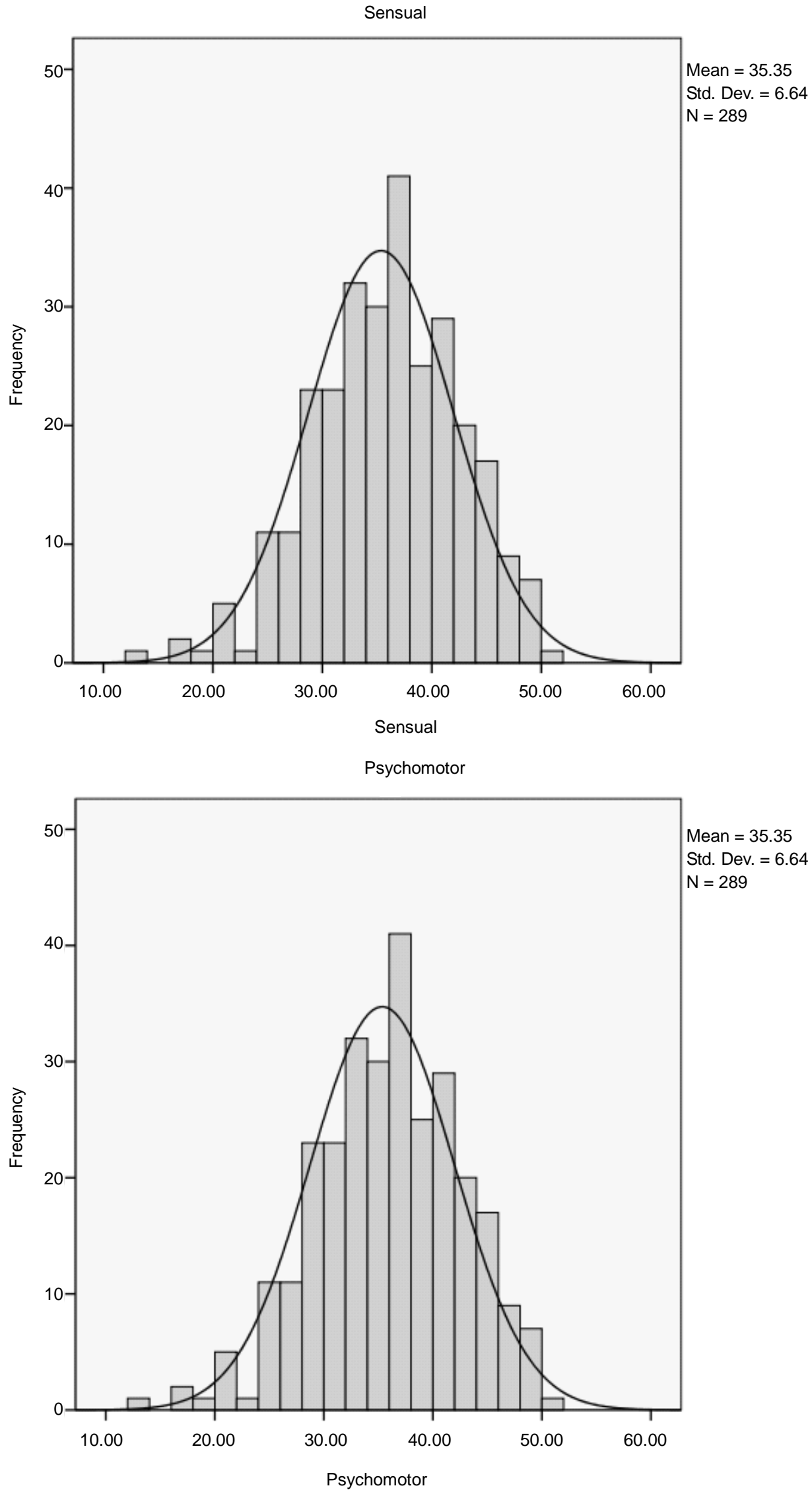
S. H. AL-ONIZAT

Imagination

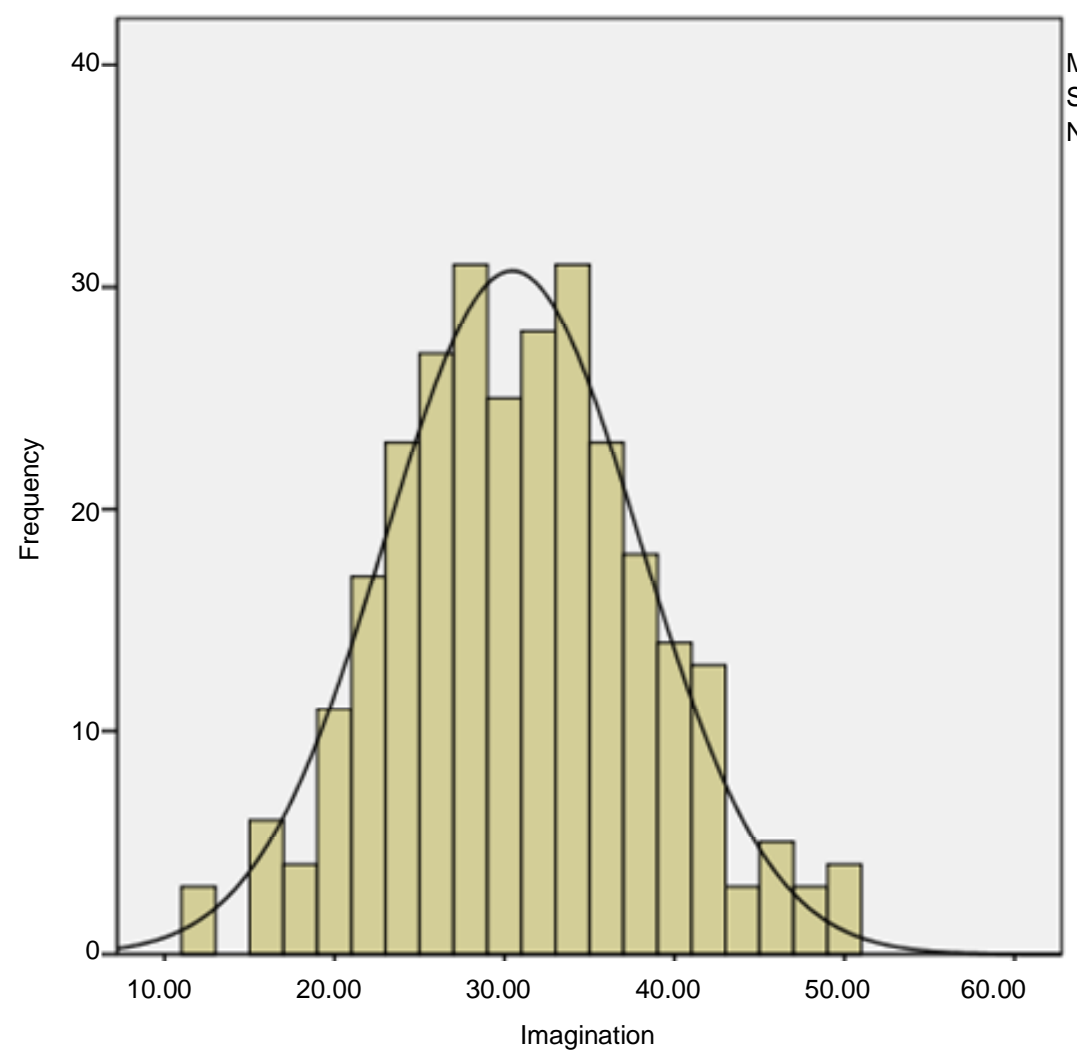

Mean $=30.45$

Std. Dev. $=7.505$

$\mathrm{N}=289$

Intellectual

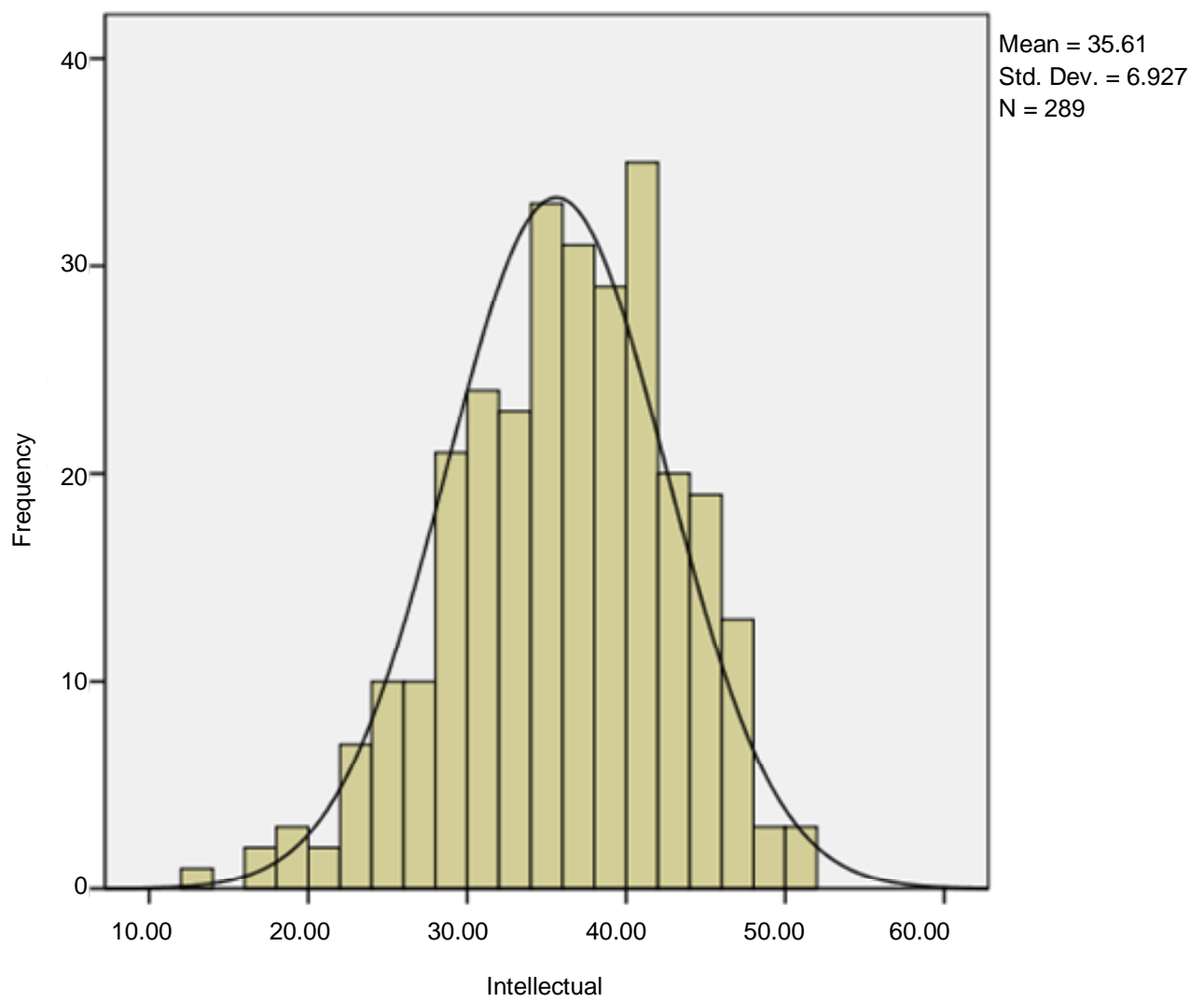



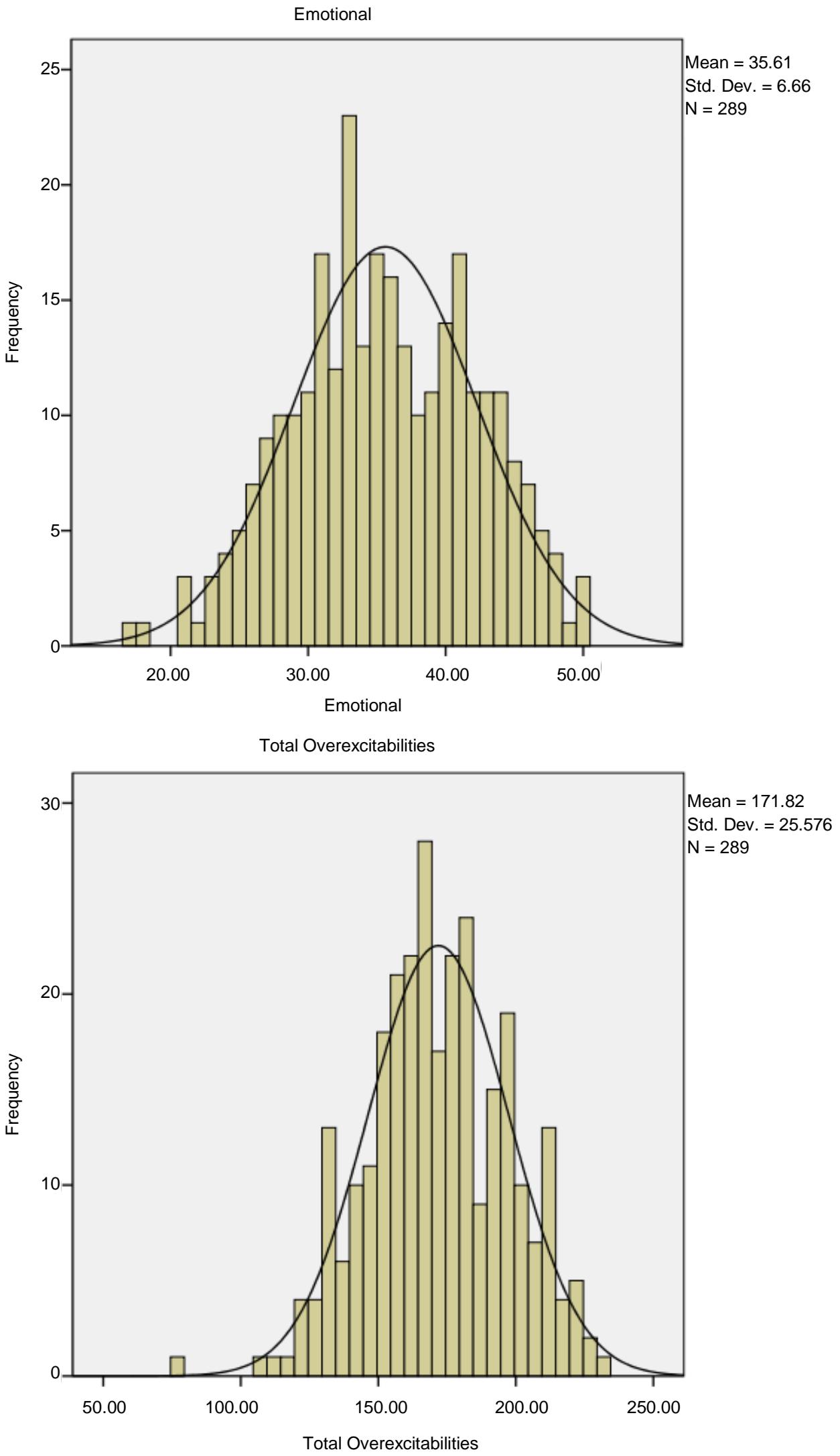

Figure 1. Shown that all of the degrees of the Overexcitabilities subscales distributed normally, and all the values of the significance level higher than 0.05 which it did not deviate in terms of statistics at the level of 0.05 for the normal distribution. 
Table 14.

The percentiles corresponding to the row degrees for each of Overexcitabilities.

\begin{tabular}{|c|c|c|c|c|c|c|c|c|c|c|}
\hline \multirow{2}{*}{ Degree } & \multicolumn{2}{|c|}{ Psychomo } & \multicolumn{2}{|c|}{ Sens } & \multicolumn{2}{|c|}{ Imagin } & \multicolumn{2}{|c|}{ Intell } & \multicolumn{2}{|c|}{ Emot } \\
\hline & Non-gift & Gift & Non-gift & Gift & Non-gif & Gift & Non-gift & Gift & Non-gift & Gift \\
\hline 11 & & & & & 0.00 & 0.00 & & & & \\
\hline 12 & & & & & 0.01 & 0.01 & & & & \\
\hline 13 & & & & & 0.01 & 0.01 & & & & \\
\hline 14 & & & & & 0.02 & 0.01 & & & & \\
\hline 15 & & & & 0.00 & 0.02 & 0.03 & & & & \\
\hline 16 & & 0.00 & & 0.01 & 0.02 & 0.03 & & & & 0.00 \\
\hline 17 & & 0.01 & & 0.01 & 0.03 & 0.05 & & 0.00 & & 0.01 \\
\hline 18 & & 0.01 & & 0.01 & 0.04 & 0.06 & & 0.01 & & 0.01 \\
\hline 19 & 0.00 & 0.01 & & 0.02 & 0.05 & 0.08 & 0.00 & 0.01 & & 0.01 \\
\hline 20 & 0.01 & 0.02 & 0.00 & 0.02 & 0.07 & 0.10 & 0.01 & 0.02 & 0.00 & 0.02 \\
\hline 21 & 0.01 & 0.03 & 0.01 & 0.03 & 0.09 & 0.13 & 0.01 & 0.02 & 0.01 & 0.03 \\
\hline 22 & 0.02 & 0.04 & 0.01 & 0.04 & 0.11 & 0.16 & 0.02 & 0.03 & 0.01 & 0.04 \\
\hline 23 & 0.02 & 0.05 & 0.02 & 0.05 & 0.14 & 0.20 & 0.02 & 0.04 & 0.02 & 0.05 \\
\hline 24 & 0.03 & 0.07 & 0.03 & 0.07 & 0.17 & 0.24 & 0.03 & 0.06 & 0.03 & 0.07 \\
\hline 25 & 0.05 & 0.09 & 0.04 & 0.09 & 0.20 & 0.28 & 0.04 & 0.08 & 0.04 & 0.09 \\
\hline 26 & 0.07 & 0.12 & 0.06 & 0.12 & 0.24 & 0.33 & 0.06 & 0.10 & 0.05 & 0.11 \\
\hline 27 & 0.09 & 0.15 & 0.08 & 0.14 & 0.29 & 0.38 & 0.08 & 0.13 & 0.07 & 0.14 \\
\hline 28 & 0.12 & 0.19 & 0.10 & 0.18 & 0.33 & 0.43 & 0.10 & 0.16 & 0.09 & 0.18 \\
\hline 29 & 0.16 & 0.23 & 0.14 & 0.21 & 0.38 & 0.49 & 0.13 & 0.20 & 0.12 & 0.21 \\
\hline 30 & 0.20 & 0.27 & 0.18 & 0.25 & 0.43 & 0.54 & 0.17 & 0.24 & 0.16 & 0.26 \\
\hline 31 & 0.25 & 0.33 & 0.22 & 0.30 & 0.49 & 0.60 & 0.20 & 0.29 & 0.20 & 0.31 \\
\hline 32 & 0.30 & 0.38 & 0.27 & 0.35 & 0.54 & 0.65 & 0.25 & 0.34 & 0.25 & 0.36 \\
\hline 33 & 0.36 & 0.44 & 0.33 & 0.40 & 0.59 & 0.70 & 0.30 & 0.39 & 0.30 & 0.41 \\
\hline 34 & 0.42 & 0.50 & 0.39 & 0.45 & 0.64 & 0.74 & 0.35 & 0.45 & 0.36 & 0.47 \\
\hline 35 & 0.48 & 0.55 & 0.46 & 0.51 & 0.69 & 0.79 & 0.40 & 0.51 & 0.42 & 0.52 \\
\hline 36 & 0.55 & 0.61 & 0.52 & 0.56 & 0.73 & 0.82 & 0.46 & 0.56 & 0.48 & 0.58 \\
\hline 37 & 0.61 & 0.67 & 0.59 & 0.61 & 0.78 & 0.86 & 0.52 & 0.62 & 0.55 & 0.63 \\
\hline 38 & 0.67 & 0.72 & 0.65 & 0.66 & 0.81 & 0.89 & 0.58 & 0.67 & 0.61 & 0.68 \\
\hline 39 & 0.73 & 0.77 & 0.71 & 0.71 & 0.85 & 0.91 & 0.63 & 0.72 & 0.67 & 0.73 \\
\hline 40 & 0.78 & 0.81 & 0.76 & 0.75 & 0.88 & 0.93 & 0.69 & 0.77 & 0.72 & 0.78 \\
\hline 41 & 0.82 & 0.85 & 0.81 & 0.79 & 0.90 & 0.95 & 0.74 & 0.81 & 0.77 & 0.82 \\
\hline 42 & 0.86 & 0.88 & 0.85 & 0.83 & 0.92 & 0.96 & 0.78 & 0.85 & 0.82 & 0.85 \\
\hline 43 & 0.89 & 0.91 & 0.89 & 0.86 & 0.94 & 0.97 & 0.82 & 0.88 & 0.86 & 0.88 \\
\hline 44 & 0.92 & 0.93 & 0.92 & 0.89 & 0.95 & 0.98 & 0.86 & 0.91 & 0.89 & 0.91 \\
\hline 45 & 0.94 & 0.95 & 0.94 & 0.91 & 0.97 & 0.99 & 0.89 & 0.93 & 0.92 & 0.93 \\
\hline 46 & 0.96 & 0.96 & 0.96 & 0.93 & 0.97 & 0.99 & 0.91 & 0.95 & 0.94 & 0.95 \\
\hline 47 & 0.97 & 0.97 & 0.97 & 0.95 & 0.98 & 0.99 & 0.93 & 0.96 & 0.96 & 0.96 \\
\hline 48 & 0.98 & 0.98 & 0.98 & 0.97 & 0.99 & 1.00 & 0.95 & 0.97 & 0.97 & 0.97 \\
\hline 49 & 0.99 & 0.99 & 0.99 & 0.99 & 0.99 & & 0.98 & 0.99 & 0.99 & 0.99 \\
\hline 50 & 1.00 & 1.00 & 1.00 & 1.00 & 1.00 & & 1.00 & 1.00 & 1.00 & 1.00 \\
\hline
\end{tabular}

Note: Non-gift: Non-gifted, gift: gifted; Psychomo: Psychomotor; Sens: Sensual; Imagin: Imagination; Intell: Intellectual; Emot: Emotional. 
S. H. AL-ONIZAT

Table 15.

The percentiles corresponding to the total row degrees for overall Overexcitabilities scale.

\begin{tabular}{|c|c|c|c|c|c|c|c|c|}
\hline Degrees & Gift & Non-gift & Degrees & Gift & Non-gift & Degrees & Gift & Non-gift \\
\hline 105 & & 0.01 & 147 & 0.15 & 0.19 & 189 & 0.73 & 0.78 \\
\hline 106 & & 0.01 & 148 & 0.16 & 0.20 & 190 & 0.74 & 0.79 \\
\hline 107 & 0.00 & 0.01 & 149 & 0.17 & 0.21 & 191 & 0.76 & 0.80 \\
\hline 108 & 0.01 & 0.01 & 150 & 0.18 & 0.22 & 192 & 0.77 & 0.81 \\
\hline 109 & 0.01 & 0.01 & 151 & 0.19 & 0.24 & 193 & 0.78 & 0.82 \\
\hline 110 & 0.01 & 0.01 & 152 & 0.20 & 0.25 & 194 & 0.79 & 0.83 \\
\hline 111 & 0.01 & 0.01 & 153 & 0.21 & 0.26 & 195 & 0.80 & 0.84 \\
\hline 112 & 0.01 & 0.01 & 154 & 0.22 & 0.27 & 196 & 0.81 & 0.85 \\
\hline 113 & 0.01 & 0.01 & 155 & 0.23 & 0.29 & 197 & 0.82 & 0.86 \\
\hline 114 & 0.01 & 0.02 & 156 & 0.25 & 0.30 & 198 & 0.83 & 0.87 \\
\hline 115 & 0.01 & 0.02 & 157 & 0.26 & 0.31 & 199 & 0.84 & 0.87 \\
\hline 116 & 0.01 & 0.02 & 158 & 0.27 & 0.33 & 200 & 0.85 & 0.88 \\
\hline 117 & 0.01 & 0.02 & 159 & 0.29 & 0.34 & 201 & 0.86 & 0.89 \\
\hline 118 & 0.01 & 0.02 & 160 & 0.30 & 0.36 & 202 & 0.87 & 0.90 \\
\hline 119 & 0.02 & 0.03 & 161 & 0.31 & 0.37 & 203 & 0.88 & 0.90 \\
\hline 120 & 0.02 & 0.03 & 162 & 0.33 & 0.39 & 204 & 0.89 & 0.91 \\
\hline 121 & 0.02 & 0.03 & 163 & 0.34 & 0.40 & 205 & 0.89 & 0.92 \\
\hline 122 & 0.02 & 0.03 & 164 & 0.36 & 0.42 & 206 & 0.90 & 0.92 \\
\hline 123 & 0.02 & 0.04 & 165 & 0.37 & 0.43 & 207 & 0.91 & 0.93 \\
\hline 124 & 0.03 & 0.04 & 166 & 0.39 & 0.45 & 208 & 0.91 & 0.93 \\
\hline 125 & 0.03 & 0.04 & 167 & 0.40 & 0.46 & 209 & 0.92 & 0.94 \\
\hline 126 & 0.03 & 0.05 & 168 & 0.42 & 0.48 & 210 & 0.93 & 0.94 \\
\hline 127 & 0.03 & 0.05 & 169 & 0.43 & 0.49 & 211 & 0.93 & 0.95 \\
\hline 128 & 0.04 & 0.05 & 170 & 0.45 & 0.51 & 212 & 0.94 & 0.95 \\
\hline 129 & 0.04 & 0.06 & 171 & 0.46 & 0.52 & 213 & 0.94 & 0.95 \\
\hline 130 & 0.04 & 0.06 & 172 & 0.48 & 0.54 & 214 & 0.95 & 0.96 \\
\hline 131 & 0.05 & 0.07 & 173 & 0.49 & 0.55 & 215 & 0.95 & 0.96 \\
\hline 132 & 0.05 & 0.07 & 174 & 0.51 & 0.57 & 216 & 0.95 & 0.96 \\
\hline 133 & 0.06 & 0.08 & 175 & 0.53 & 0.58 & 217 & 0.96 & 0.97 \\
\hline 134 & 0.06 & 0.08 & 176 & 0.54 & 0.60 & 218 & 0.96 & 0.97 \\
\hline 135 & 0.07 & 0.09 & 177 & 0.56 & 0.61 & 219 & 0.96 & 0.97 \\
\hline 136 & 0.07 & 0.10 & 178 & 0.57 & 0.63 & 220 & 0.97 & 0.98 \\
\hline 137 & 0.08 & 0.10 & 179 & 0.59 & 0.64 & 221 & 0.97 & 0.98 \\
\hline 138 & 0.08 & 0.11 & 180 & 0.60 & 0.66 & 222 & 0.97 & 0.98 \\
\hline 139 & 0.09 & 0.12 & 181 & 0.62 & 0.67 & 223 & 0.97 & 0.98 \\
\hline 140 & 0.09 & 0.13 & 182 & 0.63 & 0.69 & 224 & 0.98 & 0.98 \\
\hline 141 & 0.10 & 0.13 & 183 & 0.65 & 0.70 & 225 & 0.98 & 0.98 \\
\hline 142 & 0.11 & 0.14 & 184 & 0.66 & 0.71 & 226 & 0.98 & 0.99 \\
\hline 143 & 0.12 & 0.15 & 185 & 0.68 & 0.73 & 227 & 0.98 & 1.00 \\
\hline 144 & 0.12 & 0.16 & 186 & 0.69 & 0.74 & 228 & 0.98 & \\
\hline 145 & 0.13 & 0.17 & 187 & 0.70 & 0.75 & 229 & 0.99 & \\
\hline 146 & 0.14 & 0.18 & 188 & 0.72 & 0.76 & 230 & 1.00 & \\
\hline
\end{tabular}


The result of these study illustrate psychometric properties of OEQII when self completed by adolescent from age $15-17$, The instrument evidenced to high internal consistency by (Cronbach-a) formula ranged from 0.74 for Psychomotor Overexcitability to 0.84 for Intellectual Overexcitability, 0.91 for the whole scale. And moderate test-retest reliability over a 2-week period ranged from 0.73 for Psychomotor Overexcitability to 0.85 for Imagination Overexcitability. The whole scale was 0.85 . Also, and after translation of the test constructive validity of the scale was examined by expert judgment and pilot study, the finding indicated that the content of the Jordanian version of OEQII need to modified to match the Arabic content. Factorial validity shows that all the subscale results are greater than 0.39 which improve the scale construction, Discriminatory validity was done by examine the differences of Overexcitability degree among gifted and non-gifted students, the result show that the gifted students have high degree than non-gifted students on all of Overexcitabilities which improve the theoretical background, Also Discriminatory validity examined by the differences of Overexcitabilities degree according to the gender, the female tended to do better in the overall average of the OEQII.

And in Sensual and in Emotional Overexcitability. However, from the investigation of the OEQII validity in this study, the validated Jordanian version is effective in measuring students' Overexcitabilities in their schools. The examination and adaptation of the items revealed that, the items are matching with the Jordanian culture, which enable the Jordanian educators to use a Jordanian version of OEQII in measuring students' OE in any Jordanian region. There are several implementations of the OEQII instrument for the educators, and students. The Jordanian version of OEQII in this study provides a lot of information about the students' $\mathrm{OE}$ in their early education and in their secondary schools. This instrument can be helpful for students to understand themselves and their specific strength and weaknesses.

In the education field, the Overexcitabilities theory should be included into the educational system in Jordan in order to involve students with various activities that may be able to improve their Overexcitabilities skills.

The Arabic version of OEQII in this study provides teachers with additional information in their students' thinking and behaviorism.

\section{Recommendation of the Study}

Based on the results of this study, the following recommendations and suggestions were formulated:

1) The use of adapted and validated Jordanian version of
OEQII instrument into the consulting processes in Jordan's schools will enable the counselors and the teachers to better understand their students' Intelligences. They can use OEQII instrument to promote the use of strength-based learning activities to enhance instructional practice and personal improvement.

2) The contents of Jordanian version of OEQII need to be included into the schools' curricula, to giving attention to nature the students' various talents.

\section{REFERENCES}

Bouchet, N., \& Falk, F. (2001). The relationship among giftedness, gender, and overexcitability. Gifted Child Quarterly, 45, 260-267. doi: $10.1177 / 001698620104500404$

Clark, B. (1992). Growing up gifted, developing the potential of children to home and school (4th ed.). London: Macmillan Publishing Company.

Dabrowski, K. (1964). Positive disintegration. Boston: Little, Brown.

Dabrowski, K., \& Piechowski, M. M. (1977). Theory of levels of emotional development (Vol. 1). New York: Dabor Science Publications.

Dabrowski, K. (1996). Multilevelness of emotional and instinctive functions. Lublin: Towarzystwo Naukowe Katolickiego Uniwersytetu Lubelskiego.

Falk, R. F., Lind, S., Miller, N. B., Piechowski, M. M., \& Silverman, L. K. (1999). The Overexcitabilities Questionnaire-Two (OEQII). Denver, CO: Institute for the Study of Advanced Development.

Hollingworth, L. S. (1942). Children above 180 IQ Stanford-Binet: Origin and development. New York: World Book. doi:10.1037/13574-000

Piechowski, M., Silverman, L., \& Falk, R. (1985). Comparison of intellectually and artistically gifted on five dimensions of mental functioning. Perceptual and Motor Skills, 60, 539-549. doi:10.2466/pms.1985.60.2.539

Piechowski, M., \& Miller, N. (1994). Assessing developmental potential in gifted children: A comparison of methods. Roeper Reivew, 7, 176-180.

Piechowski, M. (2006). "Mellow out”, they say. If I only could: Intensities and sensitivities of the young and bright. Madison, WI: Yunasa books.

Renzulli, J. (1986). Systems for the gifted and talented. Mansfield, CO: Creative Learning Press, Inc.

Renzulli, J. (1978). What makes giftedness? Reexaming a definition. Phi Delta Kappan, 60, 180-184, 261.

Silverman, L. (1983). Issues in affective development of the gifted. In J. Vantassel-Baska (Eds.), A practical guide to counseling the gifted in school setting. Reston, VA: Council for exceptional children.

Silverman, L. (1993). Counseling of the gifted and talented. Denver: Love.

Tannenbaum, A. J. (1983). Gifted children. New York: Macmillan Publishing. 